\title{
Seismic Properties of Moment-resisting Timber Joints with a Combination of Bolts and Nails
}

\author{
Awaludin, A.1), Hayashikawa, T.2), Oikawa, A.2), Hirai, T.3), Sasaki, Y. (3), and Leijten, A.J.M.4)
}

\begin{abstract}
Improvement of cyclic or dynamic performance of timber connections has been intensively conducted since the overall response of wooden structures is merely a function of joint performance. For a bolted joint, filling the lead-hole clearance with epoxy resin or gluing high embedding-strength materials at the interface of the individual timber member are probably the most common methods. This study presents cyclic test results of moment-resisting joints with a combination of bolts and nails. The nails were placed closer to the joint centroid than the bolts, acting as additional fasteners and were expected to improve the seismic performance of the joints. Static-cyclic test results confirmed the increase of joint stiffness and moment resistance due to the additional nails. The nails contribute to the increase of hysteretic damping significantly though pinching behavior or narrowing the hysteresis loops close to zero rotation points was still observed. The results indicated that contribution of nails or bolts on moment resistance and hysteretic damping can be superimposed.
\end{abstract}

Keywords: Bolted joints, hysteretic damping, nails, pinching, seismic performance.

\section{Introduction}

Bolts are extensively used in timber joints as they are relatively easy and quick to install without surface preparation. For ease of assembly, usually oversized holes are pre-drilled to account for misalignment or moisture-related changes. The loaddisplacement relation of bolted joints under lateral loads is nonlinear due to nonlinear bending properties of the bolt and embedment properties of wood. In addition, the fastener slenderness ratio (the ratio of wood member thickness over the bolt diameter) and washer dimension play a crucial role in the postelastic behavior [1-3]. A minimum of $35 \%$ load increase after yielding was reported for double-shear tests with single-bolts and steel side plates [4]. This is due to the development of axial force in bolts, which is not only caused by the initial tightening but mainly by the result of joint deformation.

1 Department of Civil and Environmental Engineering, Gadjah Mada University, Yogyakarta 55281, INDONESIA.

Email: alitsipil.ugm.ac.id, ali_hokkaido@yahoo.com

${ }^{2}$ Research Faculty of Engineering, Hokkaido University, Kita 13 Nishi 8, Kita-ku, Sapporo 060-8628, JAPAN.

${ }^{3}$ Research Faculty of Agriculture, Hokkaido University, Kita 9 Nishi 9, Kita-ku, Sapporo 060-8589, JAPAN.

${ }^{4}$ Faculty of Architecture and Building Technique, Eindhoven University of Technology, Den Dolech 2, VRT 9.23, P.O. Box 513, 5600 MB Eindhoven, NETHERLANDS.

Note: Discussion is expected before June, $1^{\text {st }} 2011$, and will be published in the "Civil Engineering Dimension" volume 13, number 2, September 2011.

Received 25 May 2010; revised 10 September 2010; accepted 22 October 2010.
Under cyclic loads, the load-displacement track produces hysteresis loop caused by damping and (or) inelastic deformation. Because of the inelastic deformation, the resistance of bolted timber joints decreases when repeatedly loaded to the same displacement. The area enclosed by the loop represents the amount of energy dissipated by the joint. Hysteresis loops of bolted joints observed in cyclic tests are characterized by low initial stiffness and serious pinching, small resistance due to irrecoverable embedment of wood under the bolts $[5,6]$. In this stage, the bolts without wood support provide the sole resistance to the applied load. As the displacement increases, more wood fibers are crushed at the bearing location leading to hole elongation. The pinched region in the hysteresis loop consequently becomes longer. Pinching leads to a significant reduction in energy dissipation and eventually isolates the mass of the structure from high peak ground acceleration during earthquake events $[7,8]$.

Some methods have been proposed to improve the loading resistance or stiffness of bolted joints [9-13]. Among those methods, filling the lead-hole clearance with epoxy resin or gluing high embedding-strength materials at the interface of the individual timber member are probably the most common in practice. In this study, some nails were added to the bolted joints. The nails were not intended to prevent premature wood-splitting as ordinary reinforcements do, but it was merely to gain more joint resistance at the initial loading stage and for a better seismic performance. A combination of bolts and nails was examined on moment-resisting joints where the nails 
were placed closer to the joint centroid than the bolts. Moment-resisting joints with only bolts were also produced and tested under the same static-cyclic loading procedure for comparison.

\section{Material and Methods}

Abies sachalinensis glued-laminated timber members having moisture content of $8 \%$ and oven-dry density of $339 \mathrm{~kg} / \mathrm{m}^{3}$ were used in this study. Their dynamic elastic modulus, determined using the standard solution of the wave equation for longitudinal vibrations of a slender free-free rod; long, compared to its cross section was $10.56 \mathrm{GPa}$ with a coefficient of variation of $2.4 \%$ [14]. The joints tested in the cyclic tests were double-shear joints as shown in Fig. 1 . The vertical distance between loading points was $975 \mathrm{~mm}$ and the timber members were connected with two $12 \mathrm{~mm}$ diameter bolts. Cross-section of the middle and side members were $100 \times 280 \mathrm{~mm}^{2}$ and $50 \times 280 \mathrm{~mm}^{2}$, respectively. The holes were drilled after joint assembly by assuring no hole misalignment. Tight fit was achieved by taking the same diameter of the holes drilled and the bolt diameter.

Figure 1(b) shows the geometry of the bolted joints without and with nails considered in this study where three replicates were tested for each joint type. Both joints had almost the same geometry, except eight $4 \mathrm{~mm}$ diameter CN90 nails were inserted by hand without pre-drilled holes in the joint with nails type. Here, inserting nails closer to the joint centroid than the bolts is apparently desirable since fastener spacing requirement is proportional to fastener diameter. Bolts require larger spacing than nails which might be difficult to be achieved when bolts are placed close to the joint centroid. In addition, bolted and nailed joints have different load-slip characteristics; the nailed joints reach their yield load-carrying capacities at a lower slip than the bolted joints do. Therefore, inserting nails at a closer distance to the joint centroid than that of the bolts would ensure that maximum resistance of the joint coincides with yielding of both nails and bolts.

In the cyclic test, three displacement transducers (LVDTs) as shown in Fig. 1 were used to measure the relative slip between the main and side member, which was further used to calculate the joint rotation and translation of the rotation centre. The cyclic loading protocol consisted of four successive joint rotations of $0.01,0.02,0.03$, and 0.04 radians with three repetitions each. After performing the cyclic test, the joints were loaded monotonically until failure or the load decreased to $80 \%$ of the maximum load. Both cyclic and monotonic loading were displacement controlled and were carried out at a constant rate of $8.5 \mathrm{~mm} / \mathrm{min}$.

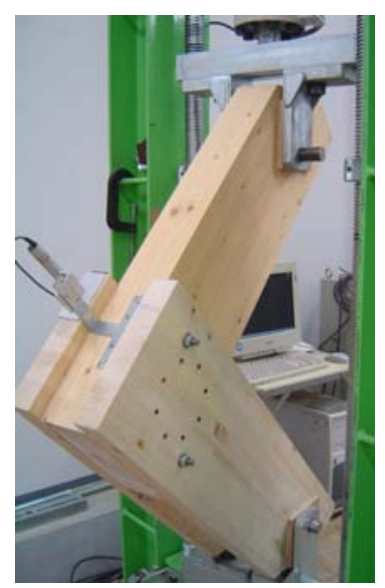

(a)

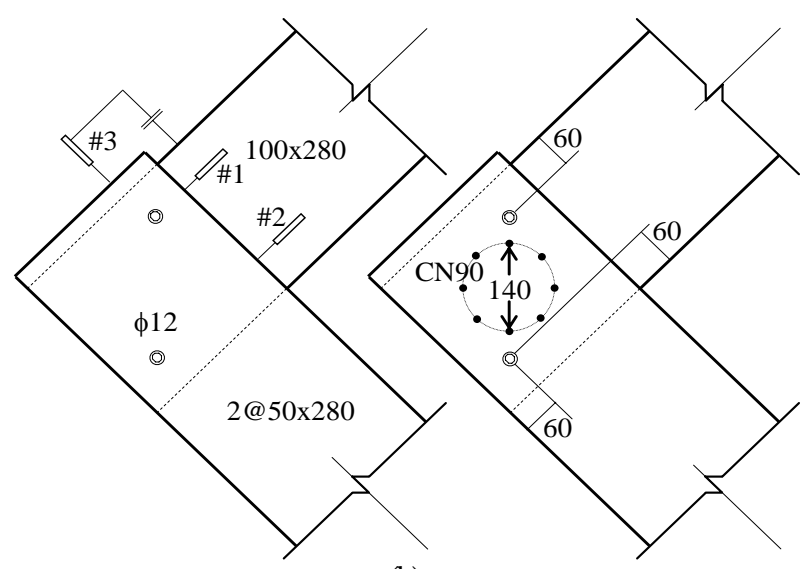

(b)

Figure 1. Cyclic test of the joints: (a) Test set up; and (b) Geometry of the bolted joint without and with nails (unit in millimeter)

\section{Results and Discussion}

\section{Hysteresis Loops}

Typical hysteretic loops of the joints obtained from the cyclic tests are shown in Fig. 2 where the loop of the joint without nail reinforcements was reversed for comparison. The joint resistance was evaluated by taking into consideration the change of lever arm due to bending deformation of timber members [15] as follows, in which some symbols are explained in Fig. 3.

$M=\bar{M} c_{1}\left(1-c_{2}\right)=F h c_{1}\left(1-c_{2}\right)$

with:

$c_{1}=\frac{\cos 0.5(\alpha+\varphi)}{\cos (0.5 \alpha)}$

$c_{2}=\frac{F h^{2} \sin 0.5(\alpha+\varphi)}{3 E I \cos ^{2}(0.5 \alpha)}$

where $\bar{M}$ is the uncorrected moment resistance, $E I$ is bending stiffness either of the main or side members. Also the center of rotation was assumed to be fixed during loading so that the joint rotation 
could be evaluated only based on two LVDTs (LVDT\#1 and \#2, see Fig. 1).

Figure 2 shows the ramp loaded bolted joint with nail reinforcements had large deformation and no visible wood cracks up to joint rotation of $0.13 \mathrm{rad}$. In contrast, the bolted joint without nail reinforcements failed at a rotation of $0.095 \mathrm{rad}$ with less inelastic bearing deformation. The rotation of $0.13 \mathrm{rad}$ corresponds to a $15 \mathrm{~mm}$ fastener slip, which is often used to evaluate the (ultimate) lateral resistance of joints. The joint with nail reinforcements showed a higher joint resistance and initial rotational stiffness than the joints without nail fasteners (Fig. 2). Maximum moment resistance of the joint without nail reinforcements was about $4.42 \mathrm{kNm}$. For the joint with nail reinforcements, the maximum resistance or moment corresponding to joint rotation of $0.13 \mathrm{rad}$ was $5.73 \mathrm{kNm}$, which is $1.31 \mathrm{kNm}$ higher than moment resistance of the joint without nail fasteners. The initial stiffness of the loops shown in Fig. 2 was around $159 \mathrm{kNm} / \mathrm{rad}$ and $280 \mathrm{kNm} / \mathrm{rad}$, respectively, for the joints without and with nails. This stiffness increase roughly was 76 percent.

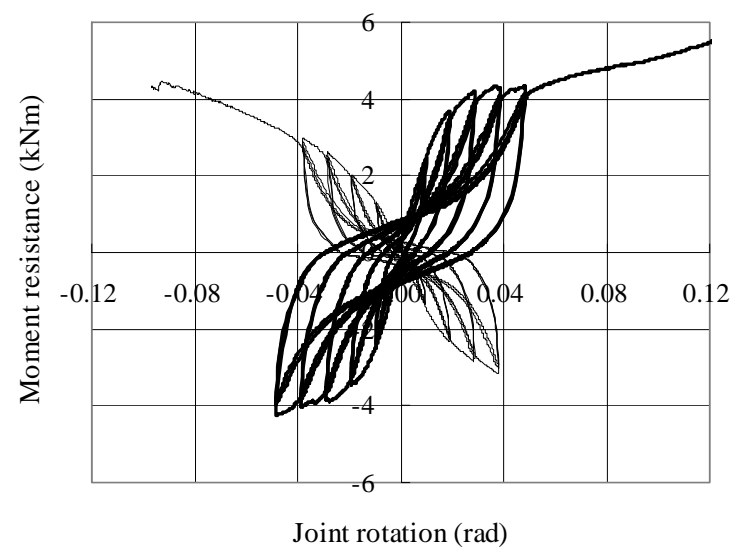

Figure 2. Experimental hysteresis loops obtained from the cyclic tests (thicker line, bolted joint with nail reinforcements)

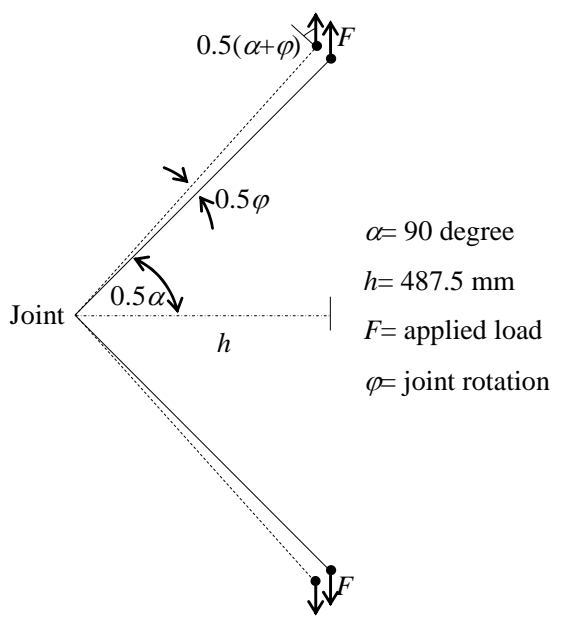

Figure 3. Change of lever arm during load application (dash-line, deformed configuration)

\section{Equivalent Viscous Damping Ratio}

The nail reinforcements contribute to the increase of hysteretic damping or area enclosed by the loop of the bolted joints though pinching behavior or narrowing the loop close to zero rotation points is still observed. Figure 4 shows the final loops of both joints at cyclic level of $0.04 \mathrm{rad}$ where hysteretic damping of the bolted joint with eight CN90 nails was about 68 percent greater than that of the bolted joint without nails. This great increase however corresponded to a small increase of equivalent viscous damping ratio of the joint; the damping ratio changed from 12 percent to 14 percent due to the additional nail reinforcements.

The equivalent viscous damping ratio was evaluated as

$$
\zeta_{\text {eq }}=\frac{1}{4 \pi} \frac{E_{\mathrm{D}}}{E_{\mathrm{P}}} \times 100 \%
$$

with $E_{\mathrm{D}}$ is the hysteretic damping and $E_{\mathrm{P}}$ is potential energy or the area of triangle shown in Fig. 5. The damping ratio given by the above equation was only an approximation because a complex damping mechanism is naturally found in doweltype timber connections [16]. This significant increase of hysteretic damping followed by a slight increase of equivalent viscous damping ratio is basically caused by the presence of pinching behavior.

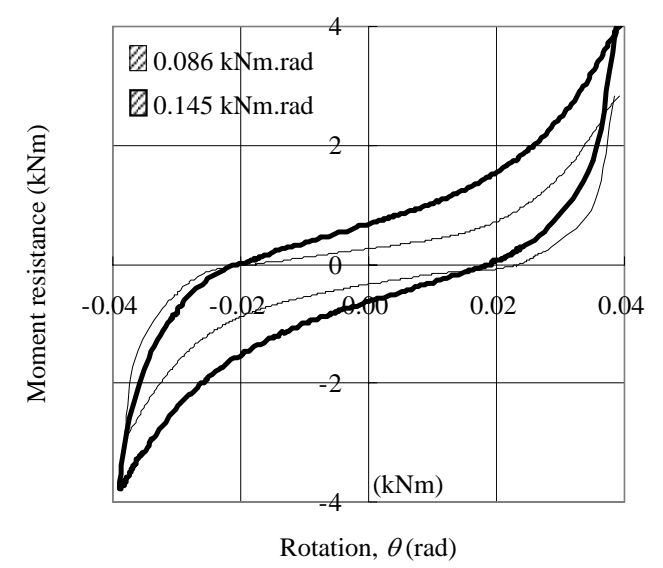

Figure 4. Final loops at cyclic rotation of $0.04 \mathrm{rad}$ (thicker line, bolted joint with nail reinforcements)

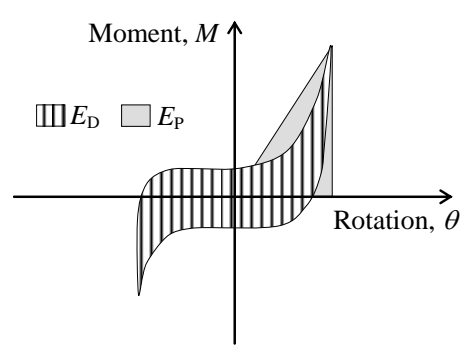

Figure 5. Definition of hysteretic properties of the joint ( $E_{\mathrm{D}}$ : hysteretic damping, $E p$ : energy potential) 


\section{Evaluation of Moment Resistance}

The moment resistance given by the nails was evaluated by summing the product of lateral force acting on each nail and distance of fastener to the centroid of the fastener pattern. It was further assumed that all nails reached their maximum loadcarrying capacities $(Z)$ expressed by the yield theory [17] as follows, in which some symbols are explained in Fig. 6.

$$
\begin{aligned}
& \int f_{h, 1} t_{1} d \\
& \mathrm{f}_{\mathrm{h}, 2} \mathrm{t}_{2} \mathrm{~d}
\end{aligned}
$$

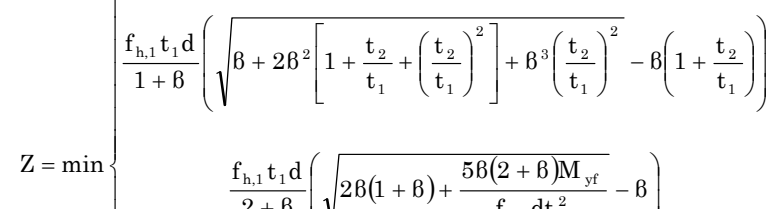

$$
\begin{aligned}
& \frac{f_{h, 1} t_{2} d}{1+2 B}\left(\sqrt{2 B^{2}(1+B)+\frac{5 B(1+2 B) M_{y f}}{f_{h, 1} d_{2}^{2}}}-B\right) \\
& \text { with: } \\
& 1.15 \mathrm{k}_{\text {cal }} \sqrt{\frac{2 B}{1+B}} \sqrt{2 \mathrm{M}_{\mathrm{yf}} \mathrm{f}_{\mathrm{h}, 1} \mathrm{~d}} \\
& f_{\mathrm{h}}=0.082 \rho d^{-0.3} \\
& \beta=\frac{f_{\mathrm{h}, 1}}{f_{\mathrm{h}, 2}} \\
& M_{\mathrm{yf}}=\frac{f_{\mathrm{u}}}{600} 180 d^{2.6}
\end{aligned}
$$

In the above equations, $f_{\mathrm{h}, 1}$ and $f_{\mathrm{h}, 2}$ are embedding strength corresponding to side and main member, respectively, $f_{u}$ is tensile strength of the nail, $\rho$ timber density in $\mathrm{kg} / \mathrm{m}^{3}, k_{\text {cal }}$ a factor to account for axial forces which develop in the nail, and $d$ is nail diameter. The yield theory proposed a set of equations based on several possible yield mechanisms. The loadcarrying capacity and the corresponding yield mode of a single-nail joint are defined by the equation that gives the lowest value.

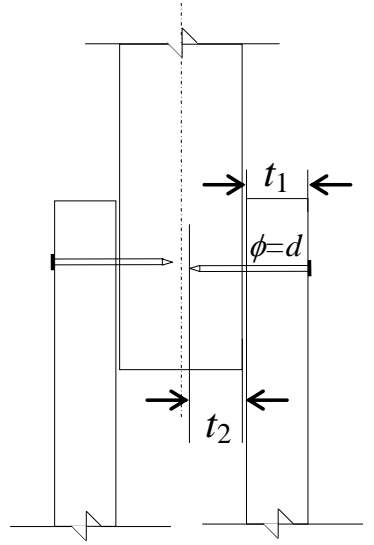

Figure 6. Geometry of single-nail joint ( $t_{1}$ : side member thickness, $t_{2}$ : point side penetration, $d$ : nail diameter)
The required information for evaluation of loadcarrying capacity of nailed joint is summarized in Table 1 . This theory predicts an additional moment resistance of $1.32 \mathrm{kNm}$, which is almost the same as the one attained from the experiment. A good agreement between the maximum joint resistance of the test and the prediction resistance demonstrated that both the contribution of nails or bolts can be superimposed.

Table 1. Geometry and material properties of the joint

\begin{tabular}{cccccc}
\hline$\rho$ & $339 \mathrm{~kg} / \mathrm{m}^{3}$ & $f_{\mathrm{u}}$ & $600 \mathrm{MPa}$ & $d$ & $4 \mathrm{~mm}$ \\
\hline$t_{1}$ & $50 \mathrm{~mm}$ & $t_{2}$ & $40 \mathrm{~mm}$ & $\beta$ & 1.00 \\
\hline
\end{tabular}

$\rho$ : timber density, $f_{\mathrm{u}}$ : tensile strength of the nail, $d$ : nail diameter, $t_{1}$ : side member thickness, $t_{1}$ : point side penetration (see Fig. 6), $\beta$ is expressed in Eq. (7)

\section{Conclusions}

The seismic performance of bolted joints with additional nails exposed to a bending was examined experimentally in this study. The nails were placed closer to joint centroid than the bolts. Cyclic test results showed that the addition of nails improved the joint resistance, initial stiffness and hysteretic damping or the area enclosed by the loop. Significant increase of hysteretic damping however was followed by a small increase of equivalent viscous damping ratio due to the presence of pinching behavior. The results indicated that contribution of nails or bolts on moment resistance and hysteretic damping can be superimposed.

\section{Acknowledgement}

This study was carried out with support from the Japan Society for the Promotion of Science.

\section{References}

1. Tsujino, T. and Hirai, T., Nonlinear Load-slip Relationship of Bolted Wood-joints with Steel Side-member I (in Japanese), Mokuzai Gakaishi, 29, 1983, pp. 833-838.

2. Kanamaru, N., Partial Bearing Characteristics of Wood (in Japanese), M.Sc Thesis, Graduate School of Agriculture, Hokkaido University, 2001.

3. Hirai, T., Nonlinear Load-slip Relationship of Bolted Wood-joints with Steel Side-member II. Mokuzai Gakaishi, 29, 1983, pp. 839-844.

4. Awaludin, A., Hirai, T., Hayashikawa, T., Sasaki, Y., Load-carrying Capacity of Steel-to-timber Joints with a Pretensioned Bolt, Journal of Wood Science, 54(5), 2008, pp. 362-368. 
5. Prion, H.G.L. and Foschi, R., Cyclic Behaviour of Dowel Type Connections, Proceedings of the Pacific Timber Engineering Conference, Gold Coast, Australia, Vol. 2, pp. 19-25, July 11-15, 1994.

6. Foliente, G.C., Hysteresis Modeling of Wood Joints and Structural Systems, Journal of Structural Engineering, ASCE, 121, 1995, pp. 1013-1022.

7. Deam, B. and King, A., The Seismic Behaviour of Timber Structures, state-of-the-art, Proceedings of the Pacific Timber Engineering Conference, Gold Coast, Australia, Vol. 1, July 11-15, 1994, pp. 215-221

8. Awaludin, A., Hayashikawa, T., Hirai T., Oikawa, A., Dynamic Response of Moment Resisting Timber Joints, Proceedings of the 8th Pacific Conference on Earthquake Engineering, Singapore, December 5-7, 2007. (CD-ROM).

9. Watanabe, H., Iimura, Y., Ultimate Behavior of Bolt Joints for Glulam Bridges under Cyclic Load, Proceedings of the 9th World Conference on Timber Engineering, Portland, August 6-10, 2006. (CD-ROM)

10. Leijten, A.J.M., Ruxton, S., Prion, H.G.L., Lam, F., Reversed-cyclic Behavior of a Novel Heavy Timber Tube Connection, Journal of Structural Engineering, ASCE, 132, 2006, pp. 1314-1319.
11. Blass, H.J., Schmid, M., Litze, H., Wagner, B., Nail Plate Reinforced Joints with Dowel-type Fasteners, Proceedings of the 6th World Conference on Timber Engineering, Whistler, July 31August 3, 2000. (CD-ROM)

12. Awaludin, A., Hirai, T., Hayashikawa, T., Sasaki, Y., Oikawa, A., Effects of Pretension in Bolts on Hysteretic Response of Moment Carrying Timber Joints, Journal of Wood Science, 54, 2008, pp. 114-120.

13. Awaludin, A., Hirai, T., Sasaki, Y., Hayashikawa, T., Oikawa, A., Beam-to-column Timber Joints with Pretensioned Bolts, Journal of Civil Engineering Dimension, 2010. (in review process).

14. Llic, J., Variation of the Dynamic Elastic Modulus and Wave Velocity in the Fibre Direction with other Properties during the Drying of Eucalyptus regnans F. Muell, Journal of Wood Science and Technology, 35, 2001, pp. 157-166.

15. Leijten, A.J.M., Densified Veneer Wood Reinforced Timber Joints with Expanded Tube Fasteners, Delft University Press, The Netherlands, 1998.

16. Chopra, A.K., Dynamics of Structures: Theory and Applications to Earthquake Engineering, Prentice Hall, Upper Saddle River, 2001, pp. 99-104.

17. European Committee for Standardization, Eurocode 5, Design of Timber Structures European Pre-standard ENV1995-1-1: General rules and rules for building, 1995. 